\title{
Call for Applications
}

\section{Pre-registered Adversarial Collaboration on Free Speech on Campus}

\section{Click here for the current version of this call}

We invite you to participate in a collaborative research effort among scholars with conflicting viewpoints to jointly devise and conduct a quantitative survey on free speech at the university.

\section{Background}

Based on a student sample from a German university, a recent study (Revers \& Traunmüller 2020) claims to have found evidence for widespread support for restricting free speech on campus, experiences of conformity pressures, and self-censorship. The study attracted broad public interest $(\underline{1}, \underline{2}, \underline{3}, \underline{5})$ along with critical reactions from other scholars $(\underline{1}, \underline{2}, \underline{\underline{4}} \underline{\text { Reply }})$. The criticism concerned issues of study design and item wording as well as the normative framing of the results. Some of the disagreement regarding the empirical findings seems to reflect differences in the researchers' epistemic, methodological, and ideological backgrounds. This call and the proposed project are motivated by the desire to leverage this diversity of perspectives in a constructive way.

\section{Adversarial Collaboration}

The goal of an adversarial collaboration is to settle or advance scholarly disputes. Coined by Daniel Kahneman (2003), adversarial collaborations bring together dissenting scholars in a "good-faith effort to conduct debates by carrying out joint research" (p. 729). Hence, the objective of this type of research enterprise is to reach a consensus on research design and inference criteria and to put one's (potentially competing) hypotheses to an empirical test (see Matzke 2015 for an example).

We will conduct an adversarial collaboration on the issue of freedom of speech on university campuses with the participation of proponents (who concur with the original study's basic conclusions) and skeptics (who do not agree with the original study's basic conclusions). In addition, an impartial referee who takes a neutral stance will mediate between the two groups in case of disagreement. The groups of proponents and skeptics will work to consent on a questionnaire and analysis plan for a quantitative survey that is to be conducted in the German university context (and potentially beyond). Before data collection, the proponents and skeptics will agree on an adversarial collaboration agreement (example) which documents in advance the details of the prospective data collection procedure, the analysis plan and analysis 
scripts along with the groups' hypotheses and the inference criteria under which the expectations would be considered supported or not supported by the data.

\section{Who can participate?}

In this open call, we are looking for scholars to join the group of skeptics.

\section{Group of skeptics}

Ideally, two to three scholars from social science disciplines with expertise in quantitative survey methodology and/or expertise in freedom of speech and/or experience with Open Science practices.

Notably, the skeptics should not agree with the original study's conclusion.

\section{Impartial referee}

Alexander Wuttke (Political psychologist, University of Mannheim; approached the original authors with the idea of an adversarial collaboration to promote Open Science practices)

\section{Group of proponents}

Richard Traunmüller (Professor of Empirical Democracy Research, University of Mannheim and coauthor of the original study)

Matthias Revers (Lecturer in Media and Communication, University of Leeds and co-author of the original study)

\section{How to apply?}

Please send an email until May 23rd to alexander.wuttke@uni-mannheim.de with a copy of your CV and a brief paragraph (250 words max.) on your scholarly background, motivation to participate in this adversarial collaboration and main critique of prior research on freedom of speech on university campuses.

You may apply individually or as a group. In case of a group application, please indicate whether you would also participate individually in a group of sceptics with other participants who were not part of your initial application.

\section{What are the next steps?}


- After the application is closed, the impartial referee will set up a team of skeptics or recommend to the team of proponents not to pursue the project further if the necessary number of researchers with relevant expertise has not been reached

- If more than three scholars apply, the impartial referee will select among the applicants based on the following criteria:

- Expertise in quantitative survey methodology

- Expertise in research on freedom of speech

- Experience with Open Science practices

- Diversity of the resulting team in terms of ideological viewpoint, gender, academic age, and geographical background

- After the impartial referee has set up a group of skeptics, the group of proponents may decide whether they are willing to take up the project with the team of skeptics selected by the referee. If they decide against it, the project will not commence, and the interested skeptics will be informed of the proponents' reasons for not starting the project.

Mid-June: First (virtual) meeting of all participants

Discussion of timeline, milestones, decision-making process etc.

\section{How did this project come about?}

\section{October 2020}

The journal Kölner Zeitschrift für Soziologie und Sozialpsychologie published the study "Is Free Speech in Danger on University Campus? Some Preliminary Evidence from a Most Likely Case" (Revers \& Traunmüller 2020)

\section{November 2020}

Controversial discussion of the study on social media and in several major German newspapers $(\underline{1}, \underline{2}, \underline{3}, \underline{4}, \underline{5})$

\section{November 2020}

Alexander Wuttke approaches Richard Traunmüller with the idea of a pre-registered adversarial collaboration

\section{April 2021}

Alexander Wuttke and Richard Traunmüller decide to set up a pre-registered adversarial collaboration. Richard Traunmüller reaches out to Matthias Revers to form the team of proponents. In consultation with Richard Traunmüller, Alexander Wuttke writes a draft on how to set up the process and for a call for applications. 